\title{
FREQUENCY OF HELMET USE AMONG MOTORCYCLE RIDERS IN RAWALPINDI
}

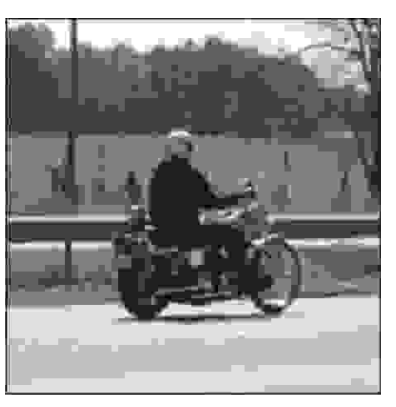

\section{DR. BABAR MUMTAZ, MPH}

Senior Lecturer

Department of Community Medicine

Foundation University Medical College

Rawalpindi

DR. MUHAMMAD HUSSAIN KHAN, FCPS

Associate Professor of Community Medicine

Foundation University Medical College

Rawalpindi

DR. MOHAMMAD WASIF KHAN, M.Sc

Associate Professor of Community Medicine

Foundation University Medical College

Rawalpindi

\author{
Dr. Mahmood Ahmed \\ DIH (UK), MCPS, DPH M.Sc (Med Adm) \\ Professor of Community Medicine \\ Foundation University Medical College \\ Rawalpindi \\ Dr. Ayesha Mahmood, MBBS \\ Demonstrator \\ Department of Community Medicine \\ Foundation University Medical College \\ Rawalpindi
}

\begin{abstract}
Objective: To find the frequence of helmet use as a safety tool and to investigate how many of the motorcyclists are aware of the beneficial effects of using a helmet. Design: A cross sectional study. Place and Duration of Study: In Community Medicine Department of Foundation University Medical College, Rawalpindi from March 2007 to September 2007. Material and Methods: A total of 1000 questionnaires were randomly distributed among motorcyclists during visits to Lalkurti, Saddar and Karchi chowk in Rawalpindi. Inclusion criteria included those motor bike rider volunteering to participate in the study.44 responses were invalid and the total valid responses were therefore 956. No incentive was offered for participation in the study and no individual follow- up was possible. Results: From a total sample size of 956 riders 541 were putting on a helmet and 415 were without the helmet. The frequence of helmet use was therefore $56.6 \%$ and that the use non user is $43.4 \%$. A bog majority i.e $80.7 \%$ of the respondents left that use of helmet while riding a motorbike should be mandatory while only $19.3 \%$ left that it should be the discretion of the riders.57.6\% of the riders left that in case of pillion riding both the riders should put on the helmet while $42.4 \%$ did not support the idea. Conclusion: The study implies that we need to enact and enforce policy intervention for mandatory use of helmet, effective traffic law enforcement and imparting awareness among our masses especially the younger generation to reduce Road Traffic Accidents. Print and electronic media should be utilize extensively to disseminate basic traffic knowledge at all levels of the society.
\end{abstract}


Key words: Helmet, Motorcyclist, Road Accident

\section{INTRODUCTION}

Road traffic accidents (RTAs) are a major cause of disability and death all over the world particularly the developing countries. World Health Organization (WHO) has recognized RTAs as a major problem. WHO projects HIVIAIDS, Unipolar depressive disorders, Ischaemic heart disease and Road traffic accidents to be the four leading causes of burden of disease by the year $2030^{1}$.

Motorcycle injuries and mortality are different in different countries depending on the use of a helmet ${ }^{2}$. In Pakistan thousands of people die every year as a result of road traffic accidents. A huge number of these deaths take place among motorcyclists riding their bikes without helmets. Studies show that countries where the use of helmet is not mandatory or if this rule was repealed the number of fatal injuries or death due to it increased many fold $^{3}$. In Pakistan the use of helmet is a mandatory for motorbike riders however poor compliance is a major problem and is a failure on the part of the traffic police.

Pakistan is the second largest country in the South Asian region with a population of 160 million. It faces all the problems being faced by rapidly developing countries especially increasing motorization. It has been established that the most common cause of head injury in road traffic accidents involved a motorcycle incident and motorcycle accident injured patients in majority of the cases are young males ${ }^{4}$. Helmet provides adequate protection, reduces severity of injury as well as medical cost.

The use of helmet as a protection gear was realized as early as 1939 but it was in 1967 that motorcycle crash helmets were made compulsory in the United Kingdom ${ }^{5}$. The economic impact of helmet use and helmet laws however remains controversial. Previous studies of injured motorcyclists suggest a marginal inpatient hospital cost difference between helmeted and unhelmeted riders ${ }^{6}$. This still needs to be explored further. Opponents believe negative findings are a result of biased statistical analyses that fails to account for the impact of alcohol and drugs ${ }^{7}$.

\section{MATERIAL AND METHODS}

This cross sectional study was conducted by the Community Medicine department of Foundation University Medical College. The objective was to find the frequency of helmet use as a safety tool and to investigation how many of the motorcyclists are aware of the beneficial effects of using a helmet. Inclusion criteria included those motor bike riders volunteering to participate in the study. One thousand questionnaires were distributed randomly among motorcyclists at Lalkurti, Saddar and Karich chowk. Questionnaires required less than 10 minutes to complete and return individually. No incentive was offered for participation in the study and no individual follow-up was possible.

The questionnaire inquired about age, sex and education of the rider. They were asked if they use a helmet, 'YES or NO'. All riders were asked to identify from a list of given options the reason for putting on or not putting on a helmet. Motorbike riders were asked wether helmet use should be mandatory for them and for the person sitting on the rear seat. The questionnaire also inquired about the need to impart awareness among motorbike riders regarding the beneficial effects of using a helmet. Some of the responses were or if the response was unidentifiable and if the response was outside the scope. 44 responses were invalid and the total valid responses were therefore 956.

\section{RESULTS}

The analysis of the data revealed that the age of the riders ranged from more than 10 to above 60 years (Figure 1). Maximum number of motorcycle riders had their education till inter $32.85 \%$ followed by matriculate $32.45 \%$ (Table I). 


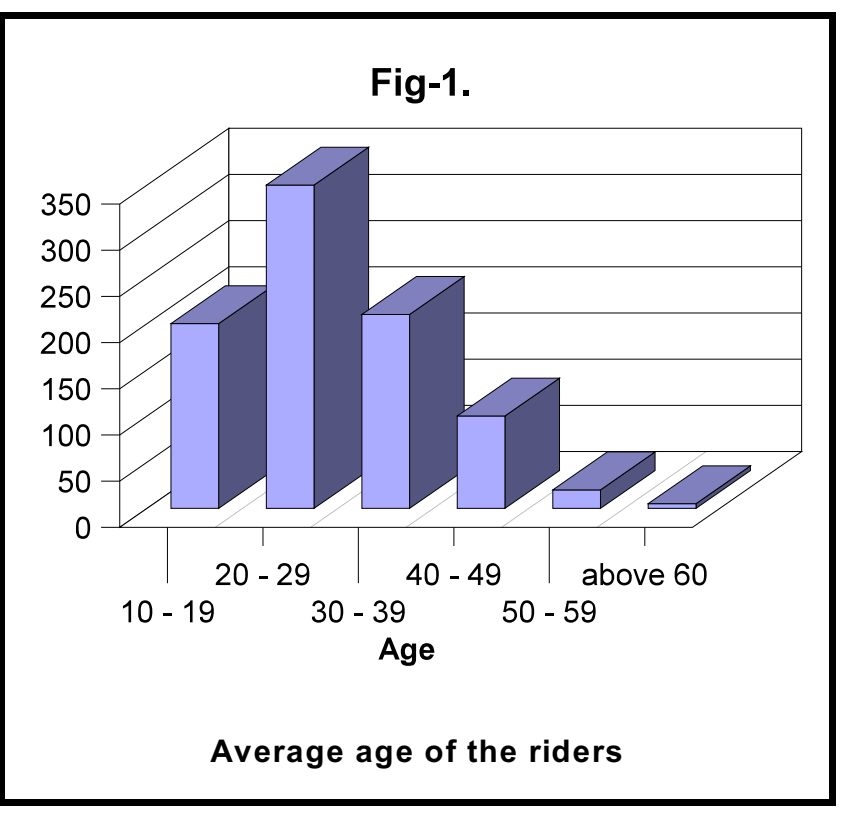

\begin{tabular}{|l|c|}
\hline \multicolumn{2}{|c|}{ Table-I. Education of the riders } \\
\hline \multicolumn{1}{|c|}{ Education } & $\%$ age \\
\hline Illiterate & $4.7 \%$ \\
\hline Middle & $8.4 \%$ \\
\hline Metric & $32.45 \%$ \\
\hline Inter & $32.85 \%$ \\
\hline Bachelor & $12 \%$ \\
\hline Masters & $8.8 \%$ \\
\hline Above Masters & $0.8 \%$ \\
\hline Total & $100 \%$ \\
\hline
\end{tabular}

\begin{tabular}{|l|c|c|c|c|c|}
\hline \multicolumn{5}{|c|}{ Table-II. } \\
\hline $\begin{array}{l}\text { Reasons for use of } \\
\text { helmet }\end{array}$ & $\begin{array}{c}\text { Protects in case of } \\
\text { accident }\end{array}$ & $\begin{array}{c}\text { It is for my own } \\
\text { safety }\end{array}$ & $\begin{array}{c}\text { Save me from } \\
\text { traffic police }\end{array}$ & $\begin{array}{c}\text { Protects from cold and } \\
\text { rain }\end{array}$ & No reason \\
\cline { 2 - 6 } & $36.7 \%$ & $44.7 \%$ & $12.2 \%$ & $2.9 \%$ & $3.5 \%$ \\
\hline $\begin{array}{l}\text { Reasons for non } \\
\text { use of helmet } \\
\% \text { age }\end{array}$ & $\begin{array}{c}\text { Helmet is very } \\
\text { expensive }\end{array}$ & $\begin{array}{c}\text { No help in case of } \\
\text { accident }\end{array}$ & $\begin{array}{c}\text { Looks awkward } \\
\text { and clumsy }\end{array}$ & $\begin{array}{c}\text { Hampers my riding } \\
\text { ability }\end{array}$ & $25.6 \%$ \\
\cline { 2 - 6 }
\end{tabular}

\begin{tabular}{|c|c|c|c|c|}
\hline \multicolumn{5}{|c|}{ Table-III. } \\
\hline \multirow{2}{*}{$\begin{array}{l}\text { Use of helmet should be } \\
\text { mandatory }\end{array}$} & \multicolumn{2}{|l|}{ Yes } & \multicolumn{2}{|l|}{ No } \\
\hline & \multicolumn{2}{|l|}{$80.7 \%$} & \multicolumn{2}{|l|}{$19.3 \%$} \\
\hline \multirow{2}{*}{$\begin{array}{l}\text { Reasons for supporting the } \\
\text { mandatory use of helmets by } \\
\text { those saying Yes }\end{array}$} & $\begin{array}{l}\text { Reduces morbidity and mortality } \\
\text { in case accident }\end{array}$ & $\begin{array}{l}\text { Mandatory in most } \\
\text { developed countries }\end{array}$ & $\begin{array}{c}\text { Very dangerous to ride bike } \\
\text { without helmet }\end{array}$ & $\begin{array}{l}\text { No } \\
\text { reason }\end{array}$ \\
\hline & $62.7 \%$ & $12.1 \%$ & $23.9 \%$ & $1.3 \%$ \\
\hline \multirow[t]{2}{*}{$\begin{array}{l}\text { Reasons for not supporting } \\
\text { the mandatory use of helmets } \\
\text { by those saying No }\end{array}$} & It is my own choice & $\begin{array}{c}\text { Useless to use a } \\
\text { helmet }\end{array}$ & $\begin{array}{l}\text { Traffic police cannot ensure } \\
\text { implementation even if made } \\
\text { mandatory }\end{array}$ & $\begin{array}{l}\text { No } \\
\text { reason }\end{array}$ \\
\hline & $44.3 \%$ & $38.9 \%$ & $10.8 \%$ & $6 \%$ \\
\hline
\end{tabular}




\begin{tabular}{|l|c|c|c|c|}
\hline \multicolumn{2}{|c|}{ Table-IV. } & \multicolumn{2}{c|}{ No } \\
\hline \multirow{2}{*}{$\begin{array}{l}\text { In case of pillion riding should both } \\
\text { riders use helmet }\end{array}$} & \multicolumn{2}{|c|}{ Yes } & \multicolumn{2}{c|}{$42.4 \%$} \\
\cline { 2 - 5 } & $57.6 \%$ & $28.1 \%$ & $6.7 \%$ & $35.8 \%$ \\
\hline \multirow{2}{*}{ How best to avoid accidents } & Enforce strict speed limits & Stringent traffic discipline & Mandatory helmet use & Don't know \\
\cline { 2 - 5 } & $29.4 \%$ & & \multicolumn{2}{c|}{ No } \\
\hline \multirow{2}{*}{$\begin{array}{l}\text { Traffic awareness be imparted } \\
\text { among riders }\end{array}$} & \multicolumn{2}{|c|}{ Yes } & \multicolumn{2}{c|}{$15.7 \%$} \\
\cline { 2 - 5 } & $84.3 \%$ & & \multicolumn{2}{|c|}{} \\
\hline
\end{tabular}

From a total sample size of 956 motorbike riders 541 were putting on a helmet and 415 were without the helmet. The frequency of helmet use in Rawalpindi is $56.6 \%$ and that of non users is $43.4 \%$. Those who were putting on the helmet were further asked to identify one reason for using the helmet and a maximum of $44.7 \%$ said that they use it as it is for their own safety. The riders that were not putting for not using a helmet and a maximum of $29.6 \%$ opted for the last option i.e'no reason' (Table II).

A big majority i.e $80.7 \%$ of the respondents felt that the helmet while riding a motorbike should be mandatory while only $19.3 \%$ felt that it should be the discretion of the riders. Those who supported the idea of mandatory use of the helmet were further asked why it should be mandatory. $62.7 \%$ said that it helps in reducing morbidity them a maximum of $44.3 \%$ said it is their own choice (Table III).

$57.6 \%$ of the riders felt that in case of pillion riding both the riders should put on the helmet while $42.4 \%$ did not support the idea and a big majority $84.3 \%$ felt that awareness should be imparted among the riders regarding the use of helmet (Table IV).

\section{DISCUSSION}

Motorize two-wheeled vehicles account for a large proportion of road traffic in Pakistan and the riders of these vehicles have a high risk of road injuries. During the last few years there has been a phenomenal increase in the sale of motorcycles in Pakistan and at the same time there has been no increase in the expenditure on road safety.

The frequency of helmet use (56.6\%) in a city like Rawalpindi would have been still lower keeping in view the fact that when this data was collected traffic police were in full swing to ensure helmet law compliance. Unfortunately these laws are not enforced with the same vigor and enthusiasm throughout the year. A study conducted in America revealed that failure to wear helmet decreases mean cost of hospitalization by more than US 6000 dollars per patient ${ }^{9}$.

Our study shows that riders who were not using a helmet out of them $25.6 \%$ said that it hampers their riding ability. Previous studies reveal that motorcyclists also complain of warm weather and reduced view due to the existing designs of helmets in Pakistan ${ }^{8}$. Research needs to be done to create a better design that is lesser in weight and affordable to the masses. Another important finding of the study is that $16.2 \%$ of the riders do not use helmet because they feel it looks awkward and clumsy. People need to be educated that helmet is for their own benefit and safety. A study published that use of helmets decrease head injuries by $85 \%$ and brain injuries by $88 \%$ for cyclists ${ }^{10}$.

An encouraging finding of the study is that $80.7 \%$ of the riders felt that the use of helmet should be mandatory while only $19.3 \%$ did not support the idea. This finding is very important as it gives an idea regarding the aptitude of the riders. As in the case of Taiwan only $21 \%$ of the motorcyclists used helmets before the strict enforcement of the motorcycle helmet law however this number 
increased drastically to $96 \%$ in Sep 1997 after the stringent implementation of the law by the traffic police ${ }^{11}$.

If we compare the results of our study with other studies regarding frequency of helmet use we find that our frequency levels are higher than most of the developing countries but we lag far behind once we compare them with developed countries. In Tehran, Iran the frequency was only $8.6 \%$ in a study conducted in $2006^{12}$. In India frequency of helmet use was found to be $31 \%$ in a study conducted in Hyderabad ${ }^{13}$. A similar type of study in Vietnam revealed that helmet use was only $29.94 \%{ }^{14}$. In Greece the overall helmet use was $20.2 \%$ ranging from $9.8 \%$ on small roads to $50.8 \%$ on highways ${ }^{15}$. In Thailand a study revealed that helmet use compliance is about $50 \%{ }^{16}$. The rate of helmet use in Londrina, Southern Brazil was $63.2^{17}$. A survey conducted in Italy revealed that only $34 \%$ motorcyclists practiced regular helmet use $^{18}$. In America despite overwhelming epidemiological evidence that motorcycle helmet laws reduce fatalities and serious injuries only 20 states currently require all riders to wear helmets ${ }^{19}$. Due to this motorcycle injuries and mortality in America are different as helmet use varies greatly depending on state laws. Helmet use is higher in New York i.e $91 \%$ and only $18 \%$ in Connecticut ${ }^{2}$. Helmet use in Florida is nearly $100 \%{ }^{20}$. In Taxes, when helmet use was made compulsory for all motorcycle operators and passengers the helmet use increased from less than $50 \%$ just before the law to $90 \%$ immediately after and it increased further to more $95 \%$ two months after ${ }^{21}$.

Conclusion: We need to inculcate knowledge regarding traffic rules and regulations in our curriculum with the objective to impart awareness at a younger age. The governmentalso mustensure provision of better facilities for the traffic police to guarantee the implementation of the traffic rules at all levels. More studies are needed to be conducted to ascertain the causes of the enormously high levels of Road Traffic Accidents in Pakistan and how best to prevent them. We need to act and act quickly to save precious lives. As a first step the government can strictly enforce helmet use with non stop consistency by all the motorcyclists which will save thousands of precious lives.

\section{REFERENCES}

1. Mathers $C D$ et al. Projections of global mortality and burden of disease from 2002 to 2030 . PloS Med. 2006 Nov;3 (11): 442-48.

2. Proscia et al. The effects of motorcycle helmet use between hospitals in states with and without a mandatory helmet law. Conn Med 2002 Apr; 66(4): 195 8.

3. Bledsoe $\mathrm{GH}$ et al. The negative impact of the repeal of the Arkansas motorcycle helmet law. J. Trauma 2002Dec;53(6):1078-86.

4. Ding SL et al. Head injuries in traffic accidents with emphasis on the comparisons between motorcyclehelmet users and non-users. J Formos Med Assoc 1994 Mar; 93 Suppl 1:S 42-8.

5. Maartens NF et al. Lawrence of Arabia, Sir Hugh Cairns, and the origin of motorcycle helmets. Neurosurgery, 2002 Jan; 50(1):176-9.

6. Eastridge BJ et al. Economic impact of motorcycle helmet: from impact to discharge. J. Trauma 2006 May:60 (5) :978-83.

7. Hundley JC et al. Non helmeted motorcyclists: a burden to society? A study using the national trauma data bank. J. Trauma 2004 Nov;57(5):944-9.

8. A. Ahmed. "Road safety in Pakistan", published by National Road Safety Secretariat, Ministry of Communications, Government of Pakistan, 2007.

9. Brandt $M M$ et al. Hospital cost is reduced by motorcycle helmet use. J. Trauma, 2002 Sep;53 (3) 469-71.

10. J. Vardy et al."Audit of an intervention to decrease cycle related head injuries in Primary School Children". Injury Prevention 2006, 12:271-73.

11. C. Wen-Ta et al. The effect of the Taiwan motorcycle helmet use law on head injuries. American Journal of Public Health 2000, 90: 793-796.

12. M. Zargar et al. Pattern of motorcycle related injuries in Tehran, 1999 to 2000: A study in six hospitals. Eastern Mediterranean Journal, 2006, Jan; 12 (1-2): 81-87. 
13. Dandona $\mathrm{R}$ et al. Risky behaviour of drivers of motorized two wheeled vehicles in India. J Safety Res, 2006; 37 (20): 149-58.

14. Hugh DV et al. Prevalence of helmet use among motorcycle riders in Vietnam. Inj Prev. 2006 Dec; 12 (6):409-13.

15. A. Skalkidou et al. Factors affecting motorcycle helmet use in the population of greater Athens, Greece. Injury Prevention, 1999, 5: 264-67.

16. J.V. Ouellet et al. Motorcycle helmet effect on a percrash basis in Thailand ans Hurt studies. Traffic Injury Prevention, 2006, 7: 1-14.

17. Liberatti et al. Helmet use by motorcyclists injured in traffic accidents in Londrina, Southern Brazil. Rev Panam Salud Publica, Jan, 2003, 13(1): 33-38.

18. A. Bianco et al. 'Adolescents' Attitude and Behaviour towards motorcycle helmet use in Italy. European Journal of Paediatrics, 2005, 164: 207-11.

19. Jones $\mathrm{MM}$ et al. Paternalism and its discontents: motorcycle helmet laws, libertarian values and public health. Am J Public Health 2007 Feb; 97(2) : 208-17.

20. Kyrychenko et al. Florida's weakened motorcycle helmet law: effects on death rates in motorcycle crashes. Traffic Inj Prev, 2006 Mar; 7 (1)55-60.

$21 \quad$ Loud AK et al. Motorcycle helmet use in Taxes. Public Health Rep. 1991 Sep-Oct; 106 (5): 576-8. 